\title{
$C$ INDEX: DIMENSIONING THE EXPEDIENT/CURATIVE CONTINUUM IN LITHIC TECHNOLOGY
}

\author{
ÍNDICE C: DIMENSIONANDO EL CONTINUUM EXPEDITIVO/CONSERVADO \\ EN LA TECNOLOGÍA LÍTICA
}

\author{
Luis E. Cornejo B. ${ }^{1}$, and Patricio Galarce C. ${ }^{2}$
}

\begin{abstract}
The technological emphasis in lithic assemblages can be examined in terms of the degree of planning each set represents and its corresponding position along the expedient/curative continuum. This approach has been a very useful analytical tool in studies of toolmaking technologies, especially among hunter-gatherer societies. In most cases, however, the approach uses qualitative criteria which, though valid, do not allow for comprehensive comparisons of different contexts. This work proposes a mechanism that is more quantitative than qualitative by offering an index that can measure the degree of curation of a given lithic assemblage. As the paper shows, we have found this development to be a useful tool for analyzing hunter-gatherer and horticulturist contexts of Central Chile.
\end{abstract}

Key words: Technological organization, lithic curation and expediency, Central Chile.

Los énfasis tecnológicos de los conjuntos líticos, vistos desde la perspectiva del grado de planificación que ellas conllevan de acuerdo al continuum expeditivo/conservado, han sido una exitosa herramienta de análisis en los estudios, especialmente de sociedades cazadoras recolectoras. No obstante, en la mayor parte de los casos su utilización se ha basado en criterios cualitativos, que, sin dejar de ser válidos, no realzan del todo el proceso de comparación entre distintos contextos. En este trabajo proponemos precisamente un mecanismo para pasar de lo cualitativo a lo cuantitativo, proponiendo un índice que mide el grado de conservación de un determinado conjunto lítico. La utilidad de este desarrollo se ejemplifica en contextos de cazadores recolectores y horticultores de Chile Central.

Palabras claves: organización de la tecnología, conservación y expeditividad, lítica, Chile Central.

Innovative approaches to the study of archaeological remains -including data collection and the construction of analytic models- have produced much of the new knowledge available of human societies of the past. In this work, we present an analytical tool we have developed to study the lithic technology of hunter-gatherers and early horticulturists of Central Chile. Our aim is to provide a systematic and quantitative grounding for certain concepts that have been in use in archaeology for more than 20 years now, especially for huntergatherer contexts, though with a more qualitative orientation. These concepts relate to aspects of lithic technology such as mobility, availability of raw materials, and the planning involved in tool use and manufacture, and are approached through the notions of curation and expediency originally developed by Binford $(1979,1980)$.

To summarize, Binford proposed (1979; 1980) (and later authors such as Bamforth (1986),
Chatters (1987), Nelson (1991), and Shott (1996) have reaffirmed) that an expedient technological strategy develops spontaneously when a human group knows that there is an abundance of suitable raw material in the place where the tools will be required for use, and when the functions for which the tools are required can be met without a high investment in flintknapping. In this scenario, the tools were disposed of after use, or once the blade lost its sharpness. At the other end of the continuum, curative strategies will become more prevalent when there is an increase in space-time incongruities between availability of raw material and the place where tools are required for use. In that case, tools were manufactured beforehand and maintained to allow for their continued reuse; they were also designed to be easy to transport and store. In general, the aim was to extract the maximum utility from tools (Shott 1996), which was usually achieved by manufacturing them through the most efficient

1 Museo Chileno de Arte Precolombino Bandera 361, Santiago, Chile. 1cornejo@ museoprecolombino.cl

2 El Rector 5035, La Florida, Santiago, Chile. patogalarce@yahoo.es. 
reduction sequences (e.g. bifacial and blade-like). Although these two technological strategies are viewed as opposites, they are often found in the same technological contexts, both forming part of a continuum in which components of each can be found represented to different degrees within the same system.

It is precisely this situation that makes it necessary to develop a way of determining the position of a given assemblage along that continuum, especially for the purpose of comparing different contexts. This paper takes a quantitative approach to determining that position, using an indexing system that we have named the $C$ Index for "Curation Index". We shall outline the features of this approach in the framework of contexts we have studied in the Andean region of Central Chile. It should be mentioned here that, while we could have designed an index to measure the degree of expediency of a given technological strategy ("Index E", for example), the scant attention paid to this strategy to date (Escola 2004) made it advisable to focus on curation, which has garnered much more recognition as a technological strategy. Furthermore, we share the conclusion of Shott (1996:268) that expediency is nothing more than low curation of tools.

The study in which this proposal developed was based on the hypothesis that hunter-gatherer populations of the Archaic tradition coexisted with horticulturist and ceramicist communities (Cornejo and Simonetti 1997-98; Cornejo and Sanhueza 2003; Saavedra and Cornejo 1995). One of the central arguments of the study is that hunter-gatherer groups displayed a technologically continuous curative strategy because of their high mobility, differentiating them from other groups that adopted an agricultural, semi-sedentary way of life, along with a mostly expedient technological strategy (Galarce et al. 2008; Miranda 2008). In fact, differences in the lithic technologies of huntergatherers and sedentary horticulturists such as those proposed here are seen to be verifiable in different contexts and locations (e.g. Price and Gebauer 1995; Stafford 1999), pointing to one of the least discussed effects of the transition from one kind of economy to the other.

The contexts examined in this study are all located in the mountains of the Maipo River valley (Central Chile) and correspond to occupational sites of hunter-gatherers and semi-sedentary horticulturists. Occupations of hunter-gatherers from the Archaic IV or Arc.IV period (3,000 to 300 years BC) are represented by the El Manzano 1 and Las Morrenas 1 shelters and the open air Holoceno site. Horticulturists of the Early Ceramic period (300 BC to 1,000 AD), PAT for "Período Alfarero Temprano" in Spanish, have been recorded at the open air sites Los Panales and El Manzano 2 and in the Río Blanco shelter. Occupations of hunter-gatherers of the Early Ceramic period or CPAT (300 BC to 1,000 AD) are represented in the upper layers of the El Manzano 1 and Las Morrenas 1 shelters. Lastly, two open air occupations of the Aconcagua Culture are included (from the Late Intermediate period, 1,000-1,470 AD, PIT for "Período Intermedio Tardío" in Spanish), the Escobarinos 1 and El Manzano 2 sites.

Given their sociocultural diversity (especially in regard to economies, mobility, and settlement patterns) and their location in a relatively circumscribed territory (the Maipo mountain valley), the occupations provide us with a good quality sample for demonstrating the usefulness and interpretative potential of the proposed methodology. Indeed, the application of the methodology in our study has led to significant discoveries about the coexistence of hunter-gatherer and early horticulturist populations in Central Chile (Cornejo and Sanhueza 2003; Galarce et al. 2008).

\section{Variables for Constructing a Curation Index}

In order to attempt to measure the degree of curation or expediency as a technological strategy, we began with the understanding that at one end of the continuum we have maximum curation, a technology associated with highly mobile groups and based strongly on the manufacture and use of bifacial tools, which are durable, easily transported, and used as part of a toolkit consisting of tools with specific functions (Kelly 1988; Nelson 1991; Tomka 2001). Curation is one of the main reductive frameworks observed in the archeological record in our area of study. The attempt to dimension the continuum in terms of bifaciality does not mean, however, that we do not recognize other variables that may come into play, such as tool diversity (Cornejo and Sanhueza 2003) or related aspects. However, by focusing on bifaciality as a derivative of the reduction process, we were able to address the issue as part of the technological decision-making process represented by each lithic assemblage, the 
toolkits of which were often the result of complex formation processes.

Our analysis, therefore, sought to determine bifacial frequency in the contexts studied by analyzing three variables of the assemblages of lithic byproducts found in those contexts (Galarce et al. 2008): raw material present, morphology of the striking platforms, and reduction categories assigned to each flintknapping byproduct analyzed. In fact, our Index could be considered as a measure of bifaciality itself; but we prefer to focus on the more heuristic capacity implied by the concepts of curation and expediency.

\section{Raw Material}

The different raw materials used to manufacture lithic tools with flaking techniques have features that make them more or less technically suitable for certain functions. Considering the complex nature of bifacial reduction, its development, the techniques applied, and manufacturing parameters, only a limited range of rocks could be used for this kind of toolmaking. In this article, we have separated raw materials according to their flintknapping quality $^{1}$, under the assumption that better quality materials would be found in closer relation to the development of bifacial sequences than would lower quality materials.

Each raw material was placed on a ranking scale that measures their suitability for bifacial work and their relation with the degree of curation of the technology for which they were required. This scale includes high quality raw material (e.g. silica and obsidian), medium quality raw material (eg. aphanitic igneous and silicified rock), and low quality raw material (e.g. porphyritic igneous rock, lithic tuff, and metamorphic rock). It should be noted that the supply of raw materials is not considered here, as the origin of most of these is unknown. Since all of the occupational sites are located within a $30 \mathrm{~km}$ radius, for this study we have assumed the existence of a relatively uniform "regional lithic landscape" (Galarce 2002, 2004; Gould and Saggers 1985) within the area itself and little variation in access to different raw materials. In the future, however, the origin of the raw materials could be incorporated as an additional variable to enrich our analytic and interpretive model.

\section{Platform Morphology}

The morphological behavior of the striking platform, the remnant of pressure flaking, provides direct evidence of the reductive process and flintknapping techniques (actions and gestures) used in working with a given piece (Andrefsky 1998, 2001). Four platform morphologies are considered (cortical, plane, faceted, and prepared), which represent a continuous succession in the development of bifacial reductive sequences, from the initial to the most advanced stages of toolmaking. Cortical and Plane platforms are associated with early stoneworking activities, while the precense of Faceted and Prepared platforms are clearly associated with advanced activities such as biface production. It is also worth noting that the category "prepared platforms" was used in a limited sense to describe platforms that were prepared by abrasion and/or grinding of their surface and the reductive elimination of the adjacent outside edge or overhang. This distinction allowed us to avoid using this category for faceted and pseudo-faceted platforms, which in our opinion are behaviorally different.

\section{Reduction Categories}

Assigning reduction categories to the byproducts of toolmaking enables us to identify the different stages of toolmaking activities represented within the reduction sequences. In this article, we have used four reduction categories: (1) Byproducts of Core Reduction: Byproducts produced by percussion flaking of a core matrix, where stone chips, slices, or angular fragments are produced as material or waste. This class of byproducts can be used to manufacture a variety of instruments or can be used as sharp edges (Andrefsky 1998; Odell 2004; Whittaker 1994). (2) Byproducts of Marginal Reduction: Byproducts resulting from percussion or pressure applied to the edges of a lithic core, flake, or blade and covering no more than half the face of the piece. Marginal debitage can be used to manufacture different classes of instruments such as terminal and lateral scrapers, serrated and notched scrapers, side scrapers, and knives, to name a few (Holdaway et al. 1996; Jackson 2002; Shott 1993, 1994). (3) Byproducts of Bifacial Reduction: Byproducts produced by the systematic application of bifacial spalling on a piece, whether core or core byproduct. These pieces have broad, sharp edges and 
therefore can be used as base forms to manufacture different types of instruments (Andrefsky 1998; Galarce 2004; Piel-Desrrouiseaux 1989; Whittaker 1994). (4) Byproducts of Bifacial Retouching: These are byproducts obtained by applying controlled percussion or pressure techniques to the edges of a biface piece during the final stage of manufacture, or during tool maintenance. Because of their small size these byproducts are usually disposed of around the tool making area itself (Andrefsky 1998; Shott 1993).

\section{Organization of Variables}

As the reader can appreciate, each case has its own criteria that can be used to organize the different expressions of the three variables according to the degree of bifaciality with which they are associated. We have organized the raw materials on the following scale, beginning with those most suitable for bifacial technology: (1) High quality, (2) Medium quality, and (3) Low quality. By using the same criteria, the different types of platforms would be organized as follows: (1) Prepared, (2) Faceted, (3) Plane, and (4) Cortical. Again, by using the same criteria, the different reduction categories would be as follows: (1) Byproducts of Bifacial Core Retouching, (2) Byproducts of Marginal Reduction, (3) Byproducts of Marginal Reduction and, lastly, (4) Byproducts of Core Reduction.

As our analysis seeks to integrate these three variables to produce a single score, we first tested whether the categories assigned to each variable were mutually compatible; in other words, whether the classification scales of the variables were mutually consistent. To determine this, we first compared the correlation (Spearman $r$ test) of absolute frequencies of lithic waste products at the sites studied for each expression of the three variables, as shown in Table 1. As the table shows, in general, our expectations were met, especially at the extreme ends of the spectrum. Thus, there is a high correlation between low quality rocks and cortical platforms that diminishes to insignificance with the increase in prepared platforms. At the other extreme, the correlation of high quality rocks increases significantly from Cortical Platforms to Prepared Platforms, and the same thing occurs in relation to reduction categories, which increase significantly as we move from Core Byproducts to Bifacial Retouching Byproducts.

By comparing only platforms and reduction categories, we also obtain expected results at both extremes. First there is a higher correlation between Cortical platforms and Core Byproducts, then a lower correlation between the same kind of platform and Bifacial Retouching Byproducts, and finally a lower correlation between Prepared Platforms and Core Byproducts and a higher correlation between that kind of platform and Bifacial Retouching Byproducts.

This bivariate analysis was complemented with a Main Component Analysis (Figure 1), in which, by crossing Factors 1 and 2 (which explain close to $86 \%$ of the set's variation), a correlation configuration is obtained that reinforces the idea that the dataset's variation is in large part a function of its relation with biface toolmaking, at least in terms of the hierarchy we are using here. Notable among these results is the formation of three variable sets that are more closely correlated internally, and more distant from those in the other sets. In Group 1, in

Table 1. Bivariate correlation between analyzed variables.

Correlación bivariada entre las variables del análisis.

\begin{tabular}{lcccccccc}
\hline & Cortical & Plane & Faceted & Prepared & Core Red. & $\begin{array}{c}\text { Marginal } \\
\text { Red. }\end{array}$ & \multicolumn{2}{c}{ Bifacial Red. Bifacial Ret. } \\
\hline Low quality & 0.949 & 0.633 & 0.605 & -0.060 & 0.784 & 0.689 & 0.267 & 0.351 \\
Medium quality & 0.534 & 0.828 & 0.771 & 0.226 & 0.813 & 0.671 & 0.476 & 0.812 \\
High quality & 0.266 & 0.619 & 0.726 & 0.873 & 0.355 & 0.643 & 0.985 & 0.903 \\
Cortical & - & - & - & - & 0.796 & 0.715 & 0.288 & 0.404 \\
Plane & - & - & - & - & 0.766 & 0.813 & 0.571 & 0.820 \\
Faceted & - & - & - & - & 0.699 & 0.793 & 0.691 & 0.868 \\
Prepared & - & - & - & - & 0.155 & 0.322 & 0.834 & 0.696 \\
\hline
\end{tabular}




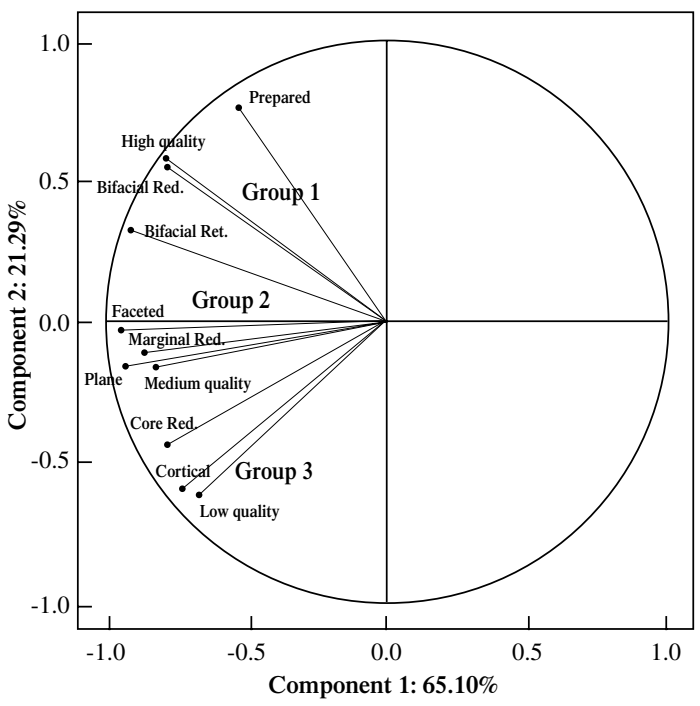

Figure 1. Main Component Analysis for different expressions of variables.

Análisis de componentes principales para las distintas expresiones de las variables.

the Component 1- and Component 2 + quadrant, we find prepared platforms, high quality raw material, and the reduction categories bifacial debitage byproducts and bifacial retouching byproducts. Two groupings are formed in the Component 1-/ Component 2-quadrant. On the one side is Group 2, with plane and faceted platforms, medium quality raw material, and reduction byproduct category marginal debitage, while Group 3 is composed of low quality raw material, core byproducts, and cortical platforms.

Group 1 would therefore correspond to the variables closest to the most suitable stones for bifacial work, while Groups 2 and 3 are more distant and in fact are ordered from more to less suitable. The faceted platform falls somewhat outside of the predicted scenario, appearing in Group 2, although the fact that its position is closest to Group 1 and more distant from Group 3 allows us to maintain its position in the order we have assigned according to technological criteria.

\section{The $C$ Index}

The index we have built fulfills two basic objectives. First, it synthesizes the three variables we have deemed suitable for dimensioning, from the perspective of bifaciality, the expedient/curative continuит. Second, it produces a single, comparable scale for any case, allowing a definitive projection of an expediency/curation curve, within which it is possible to extrapolate and interpolate values for specific hypotheses related to lithic technological strategies.

The first step in building the index involved selecting a measuring scale and assigning values within that scale for the expression of each variable analyzed. The scale chosen ranges from 0 to 1 (with values rounded to two decimal points); this not only standardized results but also enabled us to build a simple parallel scale for comparing results. Thus, a score of 1 is obtained where the technological strategy exhibits maximum curation, and a score of 0 is obtained for the inverse situation, i.e. cases of maximum expediency in the technological strategy. Obviously, these two extremes are only ideal situations, and in all real contexts the results lean towards one extreme or the other, but never with a total absence of the other strategy. A good example of this can be found in the lithic contexts of PIT Aconcagua people of Central Chile. Despite the fact that most of their tools were used with an expedient strategy, it is always possible to find biface elements too, especially projectile points made with raw materials such as obsidian and silica.

The scale of 0 to 1 can be divided into four quartiles of equal size, wherein a context with a $C$ Index between 0 and 0.25 will be classified as low curation, those with values between 0.26 and 0.50 are moderately low curation, values between 0.51 and 0.75 correspond to moderately high curation, and indices between 0.76 and 1.0 are for high curation levels. As mentioned, this rating scale will be especially useful for making comparisons.

Once this is achieved, the next step is to assign an individual position on the scale to each expression of the variables studied. As there is no present rationale for giving more weight to a particular expression of any of the three variables, the decision was made to divide the number of expressions of each variable proportionately across the index range of 0 to 1 . Thus, each expression of a variable was assigned a specific weight within the continuum according to the scale shown in Table 2. This value can be used for estimating the proportionate contribution of each of these to the index ${ }^{2}$.

With the assignation of values achieved, the next step was to determine a value for each variable in each case; we called this $C p$ or Partial Curation Index, using the following rationale. For example, 
Table 2. Ratings assigned to each expression of the three variables studied.

Valoración asignada a cada expresión de las tres variables estudiadas.

\begin{tabular}{|c|c|c|c|c|c|}
\hline \multicolumn{2}{|l|}{ Raw Material } & \multicolumn{2}{|c|}{ Platform morphology } & \multicolumn{2}{|c|}{ Reduction categories } \\
\hline Low quality & 0.25 & Cortical & 0.25 & Core Red. & 0.25 \\
\hline Medium quality & 0.75 & Plane & 0.50 & Marginal Red. & 0.50 \\
\hline \multirow[t]{2}{*}{ High quality } & 1.00 & Faceted & 0.75 & Bifacial Red. & 0.75 \\
\hline & & Prepared & 1.00 & Bifacial Ret. & 1.00 \\
\hline
\end{tabular}

if the raw material in a given context is $100 \%$ high quality, then this variable will have $100 \%$ of the value of 1.0 , in other words, $C p=1.0$. In contrast, if the data for a context falls $50 \%$ into the reduction category Marginal Debitage Byproducts, with a value of 0.5 , and the other $50 \%$ corresponds to the category Byproducts of Bifacial Retouching, with a value of 1.0 , then the corresponding $C p$ would be $0.75(50 \%$ of $0.5+50 \%$ of 1.0 , or $0.25+0.50)$. Lastly, if a given context contains $100 \%$ Cortical Platforms, with a value of 0.25 , then it would be assigned $100 \%$ of that value of 0.25 , and the $C p$ would therefore be equal to 0.25 .

Tables 3, 4, and 5 show the relative frequency of each expression of each of the three variables studied, expressed as values between 0 and 1 , for the archeological occupations studied; they also show the calculation of each's contribution to the $C p$ for each variable of each occupation studied. The Partial Curation Rating for a variable is therefore calculated using the following formula:

$$
C p=\sum V_{i} \cdot F r_{i}
$$

Where $C p$ is the Partial Rating, $V_{i}$ is the value assigned to each expression of the variable and $\mathrm{Fr}_{i}$ is the relative frequency of that variable in the context in question.

The final step in generating the $C$ Index is to integrate the values of the three variables studied. A three dimensional image of the dispersion (Figure 2) obtained for the archeological occupations studied here, based on the $C p$ values, can help us to comprehend how the cases are organized through their interaction. The reader may observe that, in general, the values are distributed more or less in the center of the three dimensional space, following a line that rises from the PAT occupation of the El Manzano 2 site, which, according to this representation, has a lower curation rating, to the Archaic IV occupation of the El Manzano 1 site, which corresponds to a higher degree of lithic technological curation. This spatial distribution may be difficult to interpret, however, and therefore we felt it was advisable to simplify the interpretation by integrating the three variables into a single measurement: the $C$ Index.

This index will be the calculated as the central position of each case in the cluster of points shown in Figure 3, which corresponds to the average of the three $C p$ values previously obtained using the formula:

$$
C=\frac{\sum C p_{i}}{3}
$$

where $C$ is the Curation Index and $C p_{i}$ is the Partial Index for each variable.

However, if we wish to allow for the possibility of assigning more weight to one or more of the variables considered, a definitive formula for calculating $C$ would be:

$$
C=\frac{\sum\left(C p_{i} \cdot \Delta\right)}{3}
$$

where $C$ is the Curation Index, $C p_{i}$ is the Partial Index of each variable used, and $\Delta$ is the weight assigned to each variable. The value of $\Delta$ will be 1.0 for each variable when all of them have equal weight, and will be a certain fraction of that amount when it is deemed necessary to assign a given variable more weight than the others. Thus, if we want to give a certain variable $20 \%$ more weight than the others, the value of $\Delta$ will be 1.2. The overweight assigned to specific variables should in no case lead to a $C p$ for any variable greater than 1.0 , as 1.0 is the maximum curation value in our model.

For the occupations studied all variables have the same weight. Table 4 shows the $C$ Index for each of those archeological occupations and $C p$ values for the three variables of each occupation. 


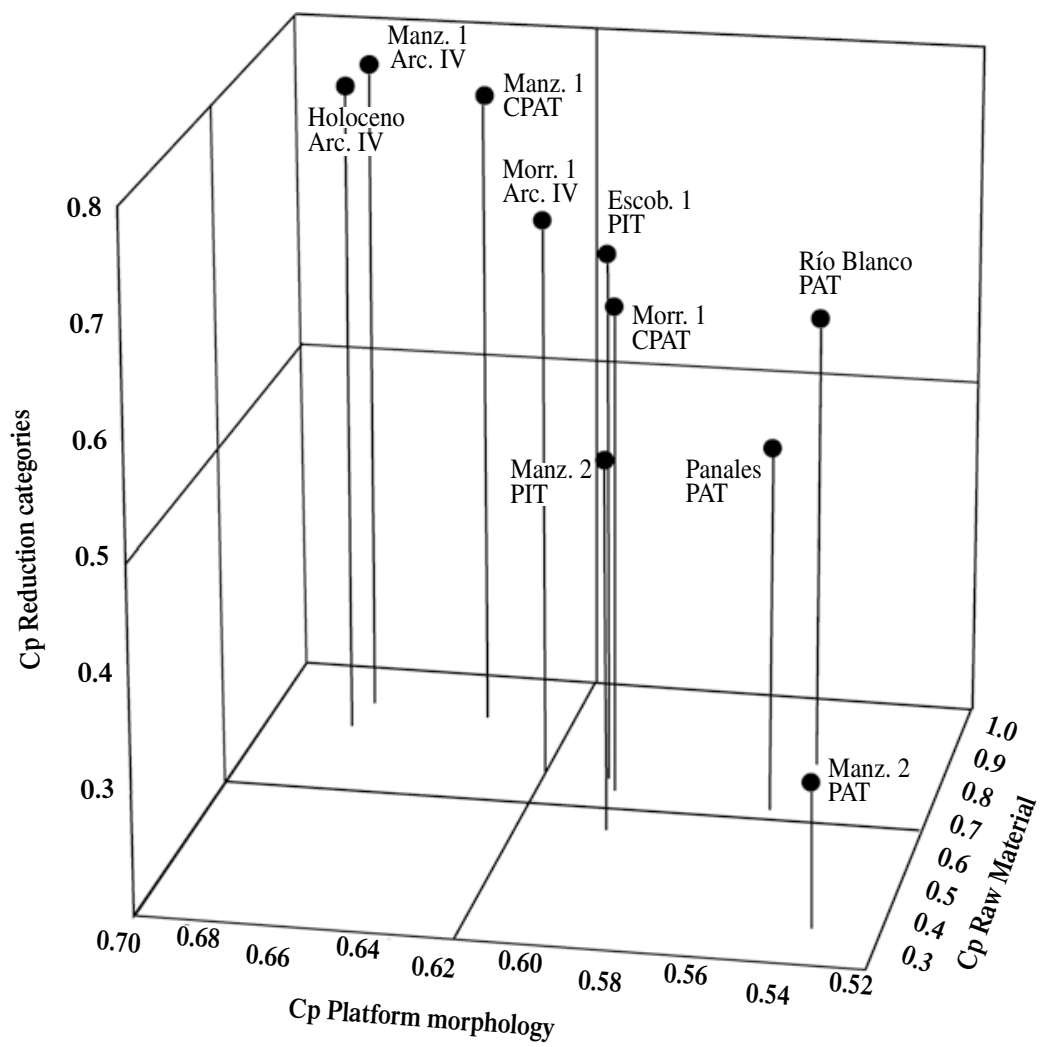

Figure 2. Three dimensional image of the relation of variables studied for the different occupations.

Representación tridimensional de la relación entre las variables estudiadas en las distintas ocupaciones.

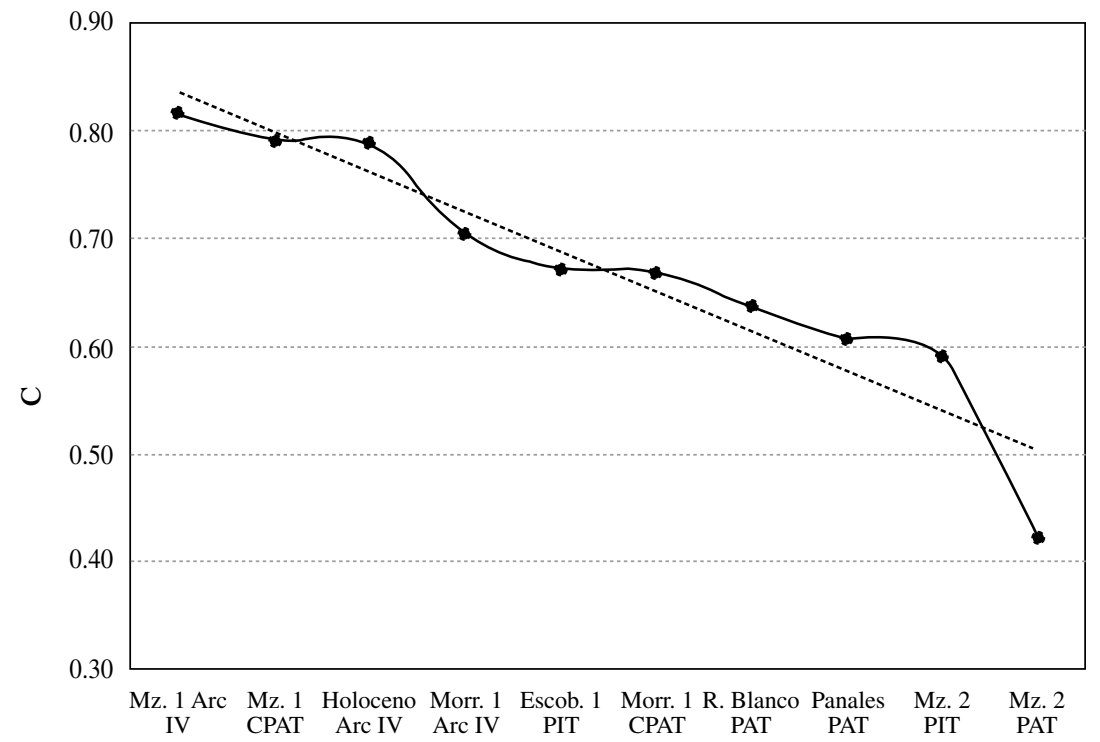

Figure 3. $C$ Index curve calculated for occupations studied and line showing the trend of the entire set.

Curva del Índice C calculado para las ocupaciones estudiadas y recta de la tendencia representada por el conjunto. 
Table 3. $C p$ index calculation for variable Raw Materials in occupations studied.

Cálculo de Índice Cp para la variable Materias Primas en las ocupaciones estudiadas.

\begin{tabular}{|c|c|c|c|c|c|c|c|c|c|c|}
\hline $\begin{array}{l}\text { Relative } \\
\text { Frequency }\end{array}$ & $\begin{array}{l}\text { R. Blanco } \\
\text { PAT }\end{array}$ & $\begin{array}{c}\text { Escob. } 1 \\
\text { PIT }\end{array}$ & $\begin{array}{c}\text { Holoceno } \\
\text { Arc IV }\end{array}$ & $\begin{array}{c}\text { Panales } \\
\text { PAT }\end{array}$ & $\begin{array}{c}\text { Manzano } 1 \\
\text { Arc IV }\end{array}$ & $\begin{array}{c}\text { Manzano } 1 \\
\text { CPAT }\end{array}$ & $\begin{array}{c}\text { Manzano } 2 \\
\text { PAT }\end{array}$ & $\begin{array}{c}\text { Manzano } 2 \\
\text { PIT }\end{array}$ & $\begin{array}{c}\text { Morrenas } 1 \\
\text { Arc IV }\end{array}$ & $\begin{array}{c}\text { Morrenas } 1 \\
\text { CPAT }\end{array}$ \\
\hline Low quality & 0.228 & 0.217 & 0.055 & 0.095 & 0.006 & 0.033 & 0.733 & 0.362 & 0.254 & 0.280 \\
\hline Medium quality & 0.411 & 0.425 & 0.180 & 0.753 & 0.019 & 0.046 & 0.186 & 0.334 & 0.043 & 0.067 \\
\hline High quality & 0.361 & 0.358 & 0.765 & 0.152 & 0.975 & 0.921 & 0.081 & 0.304 & 0.703 & 0.653 \\
\hline $\mathbf{N}$ & 523 & 2.393 & 4.718 & 453 & 1.207 & 305 & 296 & 746 & 1.454 & 1.448 \\
\hline \multicolumn{11}{|l|}{ Ratings } \\
\hline Low quality & 0.057 & 0.054 & 0.014 & 0.024 & 0.001 & 0.008 & 0.183 & 0.090 & 0.064 & 0.070 \\
\hline Medium quality & 0.308 & 0.318 & 0.135 & 0.565 & 0.014 & 0.034 & 0.139 & 0.250 & 0.032 & 0.050 \\
\hline High quality & 0.361 & 0.358 & 0.765 & 0.152 & 0.975 & 0.921 & 0.081 & 0.304 & 0.703 & 0.653 \\
\hline$C p$ Index & 0.727 & 0.731 & 0.914 & 0.741 & 0.991 & 0.964 & 0.404 & 0.645 & 0.798 & 0.773 \\
\hline
\end{tabular}

Note: The values represented here are rounded to three decimal places. For this reason, the direct sum of the values presented here may not match in the third decimal

Table 4. $C p$ index calculation for the variable Platform type in the occupations studied.

Cálculo de Índice Cp para la variable tipo de Plataforma en las ocupaciones estudiadas.

\begin{tabular}{|c|c|c|c|c|c|c|c|c|c|c|}
\hline $\begin{array}{l}\text { Relative } \\
\text { Frequency }\end{array}$ & $\begin{array}{l}\text { R. Blanco } \\
\text { PAT }\end{array}$ & $\begin{array}{c}\text { Escob. } 1 \\
\text { PIT }\end{array}$ & $\begin{array}{c}\text { Holoceno } \\
\text { Arc IV }\end{array}$ & $\begin{array}{c}\text { Panales } \\
\text { PAT }\end{array}$ & $\begin{array}{c}\text { Manzano } 1 \\
\text { Arc IV }\end{array}$ & $\begin{array}{c}\text { Manzano } 1 \\
\text { CPAT }\end{array}$ & $\begin{array}{c}\text { Manzano } 2 \\
\text { PAT }\end{array}$ & $\begin{array}{c}\text { Manzano } 2 \\
\text { PIT }\end{array}$ & $\begin{array}{c}\text { Morrenas } 1 \\
\text { Arc IV }\end{array}$ & $\begin{array}{c}\text { Morrenas } 1 \\
\text { CPAT }\end{array}$ \\
\hline Cortical & 0.056 & 0.078 & 0.037 & 0.055 & 0.022 & 0.036 & 0.153 & 0.151 & 0.096 & 0.131 \\
\hline Plane & 0.731 & 0.440 & 0.360 & 0.733 & 0.415 & 0.439 & 0.622 & 0.498 & 0.386 & 0.408 \\
\hline Faceted & 0.181 & 0.483 & 0.461 & 0.129 & 0.406 & 0.439 & 0.148 & 0.160 & 0.456 & 0.380 \\
\hline Prepared & 0.033 & 0.000 & 0.142 & 0.083 & 0.158 & 0.086 & 0.077 & 0.191 & 0.061 & 0.081 \\
\hline $\mathbf{N}$ & 360 & 2.393 & 2.134 & 326 & 1.206 & 303 & 193 & 550 & 1.126 & 1.102 \\
\hline \multicolumn{11}{|l|}{ Ratings } \\
\hline Cortical & 0.014 & 0.019 & 0.009 & 0.014 & 0.005 & 0.009 & 0.038 & 0.038 & 0.024 & 0.033 \\
\hline Plane & 0.365 & 0.220 & 0.180 & 0.367 & 0.207 & 0.219 & 0.311 & 0.249 & 0.193 & 0.204 \\
\hline Faceted & 0.135 & 0.362 & 0.346 & 0.097 & 0.305 & 0.329 & 0.111 & 0.120 & 0.342 & 0.285 \\
\hline Prepared & 0.033 & 0.000 & 0.142 & 0.083 & 0.158 & 0.086 & 0.077 & 0.191 & 0.061 & 0.081 \\
\hline$C p$ Index & 0.548 & 0.601 & 0.677 & 0.560 & 0.675 & 0.644 & 0.537 & 0.598 & 0.621 & 0.602 \\
\hline
\end{tabular}

Note: The values represented here are rounded to three decimal places. For this reason, the direct sum of the values presented here may not match in the third decimal.

Table 5. $C p$ index calculation for variable Reductive Category type in occupations studied.

Cálculo de Índice Cp para la variable tipo de Categoría Reductiva en las ocupaciones estudiadas.

\begin{tabular}{|c|c|c|c|c|c|c|c|c|c|c|}
\hline $\begin{array}{l}\text { Relative } \\
\text { Frequency }\end{array}$ & $\begin{array}{c}\text { Río Blanco } \\
\text { PAT }\end{array}$ & $\begin{array}{c}\text { Escob. } 1 \\
\text { PIT }\end{array}$ & $\begin{array}{c}\text { Holoceno } \\
\text { Arc IV }\end{array}$ & $\begin{array}{c}\text { Panales } \\
\text { PAT }\end{array}$ & $\begin{array}{c}\text { Manzano } 1 \\
\text { Arc IV }\end{array}$ & $\begin{array}{c}\text { Manzano } 1 \\
\text { CPAT }\end{array}$ & $\begin{array}{c}\text { Manzano } 2 \\
\text { PAT }\end{array}$ & $\begin{array}{c}\text { Manzano } 2 \\
\text { PIT }\end{array}$ & $\begin{array}{c}\text { Morrenas } 1 \\
\text { Arc IV }\end{array}$ & $\begin{array}{c}\text { Morrenas } 1 \\
\text { CPAT }\end{array}$ \\
\hline Core Red. & 0.072 & 0.258 & 0.088 & 0.397 & 0.080 & 0.063 & 0.760 & 0.501 & 0.108 & 0.194 \\
\hline Marginal Red. & 0.570 & 0.172 & 0.093 & 0.227 & 0.120 & 0.162 & 0.189 & 0.168 & 0.194 & 0.237 \\
\hline Bifacial Red. & 0.095 & 0.157 & 0.446 & 0.268 & 0.409 & 0.436 & 0.034 & 0.052 & 0.518 & 0.436 \\
\hline Bifacial Ret. & 0.263 & 0.413 & 0.372 & 0.108 & 0.391 & 0.340 & 0.017 & 0.279 & 0.181 & 0.132 \\
\hline $\mathbf{N}$ & 528 & 2.393 & 4.522 & 418 & 1.207 & 303 & 296 & 746 & 1.450 & 1.442 \\
\hline \multicolumn{11}{|l|}{ Ratings } \\
\hline Core Red. & 0.018 & 0.065 & 0.022 & 0.099 & 0.020 & 0.016 & 0.190 & 0.125 & 0.027 & 0.049 \\
\hline Marginal Red. & 0.285 & 0.086 & 0.047 & 0.114 & 0.060 & 0.081 & 0.095 & 0.084 & 0.097 & 0.119 \\
\hline Bifacial Red. & 0.071 & 0.118 & 0.335 & 0.201 & 0.307 & 0.327 & 0.025 & 0.039 & 0.388 & 0.327 \\
\hline Bifacial Ret. & 0.263 & 0.413 & 0.372 & 0.108 & 0.391 & 0.340 & 0.017 & 0.279 & 0.181 & 0.132 \\
\hline Índice $C p$ & 0.637 & 0.681 & 0.775 & 0.522 & 0.778 & 0.763 & 0.327 & 0.527 & 0.693 & 0.627 \\
\hline
\end{tabular}

Note: The values represented here are rounded to three decimal places. For this reason, the direct sum of the values presented here may not match in the third decimal 
These values can be mapped along a continuиm ranging from 0.0 to 1.0 , describing a specific curve for the set of cases studied. This is represented in the Figure 3 graph as a continuous line, and allows us to calculate the general trend for the entire set, which is represented as the broken line in the same Figure 3.

Table 4 also shows the ordinal values for each occupation, which in this case are distributed as follows: moderately Low curation in the PAT occupation of El Manzano 2; moderately high in the PIT occupation of El Manzano 2 and the PAT occupations of Los Panales, Rio Blanco and Las Morrenas 1, the PIT occupation of Escobarinos and Archaic IV occupation of Las Morrenas 1; and high curation in the Archaic IV Holoceno occupations, the PAT occupation of El Manzano 1, and the Archaic occupation of El Manzano 1.

\section{Discussion and Conclusions}

The data presented here show that it is possible to represent in a simplified manner the complex set of technological decisions and strategies adopted for stone tool use by different populations. We can gain understanding of the data by examining the problem that led us to develop this instrument and appreciating its potential for analyzing lithic technology itself.

Our original hypothesis (Cornejo and Sanhueza 2003), while it also included information on ceramics and on different types of occupied sites, pointed to a marked difference between the lithic technological strategy of two populations that coexisted during the Early Ceramic period in Central Chile, one a markedly curative case and the other clearly expedient. It was precisely this that motivated us to seek a way of dimensioning these differences, knowing that they naturally form a continuum of strategies but could also be rated on a scale to allow clearer comparisons among them.

Observing the location of each occupation on the scale produced by the $C$ Index (Figure 3 ), we can distinguish a couple of elements that have been central to our hypothesis. On the one hand, the open air occupations from PAT, which can be assigned to semi-sedentary horticulturists (El Manzano 2 PAT and Los Panales), are located in the lowest part of the scale, while, on the other hand, contemporary occupations located in nearby shelters, which we have interpreted as hunter-gatherer, are found higher on the scale (El Manzano 1 PAT and Las Morrenas 1 PAT). The latter, in turn, obtain $C$ scores similar to hunter-gatherer occupations from the Archaic IV period (3,000 to 300 B.C,), located in both the same shelters (El Manzano 1 and Las Morrenas 1), and at open air sites (Holoceno). This provides crucial support to our hypothesis, which seeks to confirm the Archaic roots of the hunters of the Early Ceramic period (Galarce et al. 2008).

Furthermore, the inclusion of other populations in this analysis -represented in the Aconcagua Escobarinos 1 and El Manzano 2 PIT sites- allows us to appreciate that the relation between strategies of subsistence and technological organization is complex and not necessarily unilineal. The position that the first site obtains in the $C$ Index places it closer to the values of hunter-gatherer sites, even though this is a later occupation than those of the Early Ceramic period and represents a population that is more sedentary and more dependent on crops than previous groups. At the same time, though both open air occupational sites are located in relatively similar locations, they present relatively dissimilar $C$ Indexes; as mentioned, one index is closer to hunter-gatherer groups from the Archaic and Early Ceramic periods, while the other is closer to the value of the Early Ceramic Horticulturists. These differences could be associated with differences in the specific functions of these occupational sites.

Interestingly, these results coincide with those of the analytical method used to construct the original hypothesis, which looked at technological differences among the populations studied relative to the diversity of formal tools in each context. It was proposed (Cornejo and Sanhueza 2003) that, given their curative nature, the hunter-gatherer contexts of both the Archaic IV and Early Ceramic periods would have had much more diverse toolkits than horticulturist contexts, and was represented using Shannon and Weaver's H Diversity Index. Now, correlating the $C$ values with $\mathrm{H}$ values (Table 6 and Figure 4), an $\mathrm{r}^{2}$ value of 0.58 is obtained, which allows us to assume that the variation of measurements is a $60 \%$ ratio of one to the other, and supports the idea that the degree of curation of a lithic strategy is related to the diversity of stone tools in the case studied.

We, therefore, believe that this Index can serve as an instrument of comparison between different 
Table 6. $C p$ indexes and $C$ index of each of the occupations studied. Índices $\mathrm{Cp}$ e Índice $\mathrm{C}$ de cada una de las ocupaciones estudiadas.

\begin{tabular}{lccccc}
\hline Site & $C p$ Raw Materials & $C p$ Platforms & $C p$ Reduction categories & $C$ Index & Ordinal scale \\
\hline Manzano 2 PAT & 0.404 & 0.537 & 0.327 & $\mathbf{0 . 4 2}$ & Moderately Low \\
Manzano 2 PIT & 0.645 & 0.598 & 0.527 & $\mathbf{0 . 5 9}$ & Moderately high \\
Panales PAT & 0.741 & 0.560 & 0.522 & $\mathbf{0 . 6 1}$ & Moderately high \\
Río Blanco PAT & 0.727 & 0.548 & 0.637 & $\mathbf{0 . 6 4}$ & Moderately high \\
Morrenas CPAT & 0.773 & 0.602 & 0.627 & $\mathbf{0 . 6 7}$ & Moderately high \\
Escob. 1 PIT & 0.731 & 0.601 & 0.681 & $\mathbf{0 . 6 7}$ & Moderately high \\
Morrenas Arc IV & 0.798 & 0.621 & 0.693 & $\mathbf{0 . 7 0}$ & Moderately high \\
Holoceno Arc IV & 0.914 & 0.677 & 0.775 & $\mathbf{0 . 7 9}$ & High \\
Manzano 1 CPAT & 0.964 & 0.644 & 0.763 & $\mathbf{0 . 7 9}$ & High \\
Manzano 1 Arc IV & 0.991 & 0.675 & 0.778 & $\mathbf{0 . 8 1}$ & High \\
\hline
\end{tabular}

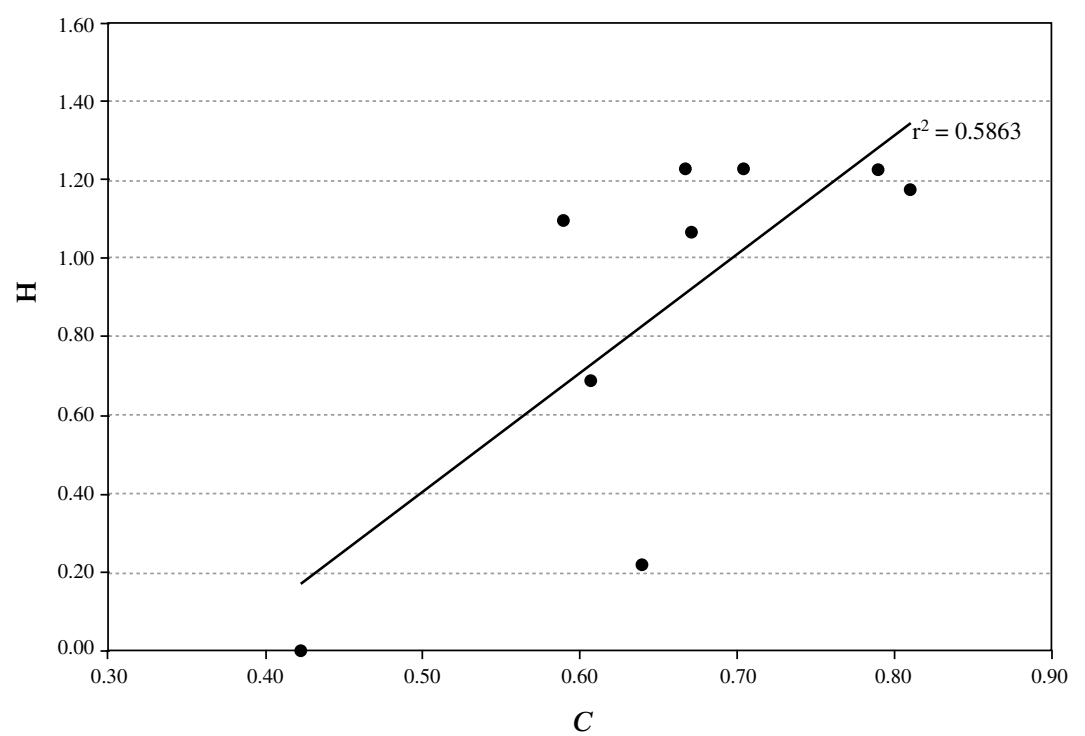

Figure 4. Regression between Curation $(C)$ and Diversity $(\mathrm{H})$. Regresión entre Conservación (C) y Diversidad $(H)$.

Table 7. Curative and Diversity indexes of occupations studied.

Índices de Curatividad y Diversidad de las ocupaciones estudiadas.

\begin{tabular}{lcc}
\hline & $C$ & $\mathrm{H}$ \\
\hline Manzano. 2 PAT & 0.42 & 0.00 \\
Manzano. 2 PIT & 0.59 & 1.10 \\
Panales PAT & 0.61 & 0.69 \\
R. Blanco PAT & 0.64 & 0.22 \\
Morrenas CPAT & 0.67 & 1.23 \\
Escob. 1 PIT & 0.67 & 1.07 \\
Morrenas Arc IV & 0.70 & 1.23 \\
Holoceno Arc. IV & 0.79 & 1.22 \\
Manzano 1 CPAT & 0.79 & 1.23 \\
Manzano Arc IV & 0.81 & 1.18 \\
\hline
\end{tabular}

technological trends, based on a quantitative scale that synthesizes various aspects of lithic technology. This tool not only can be used for intercultural comparisons but it also allows us to observe variations in the same technological system over a given territory, as it is to be expected that sites with distinct functionalities would present technological differences. Indeed, this has been shown in comparisons of Archaic and Early Ceramic hunter-gatherer occupations of the El Manzano 1, Las Morrenas 1, and Holoceno sites. Each of these cases produced $C$ values that were close on the overall scale but display differences that could be explored in the future to help us understand the occupational patterns of these human groups. 
Acknowledgements: This work was made possible through FONDECYT grant 1060228. We wish to thank Lorena Sanhueza R. for her valuable comments on the manuscript and the anonymous referees for their very enriching contributions. Dan Sandweiss, member of the Editorial Committee of Chungara, make a very useful comment to final version of the manuscript.

\section{References Cited}

Andrefsky, W.

1998 Lithics: Macroscopic Approaches to Analysis. Manuals Cambridge in Archaeology. Cambridge University Press, Cambridge.

2001 Emerging directions in debitage analysis. In Lithic Debitage: Context, Form and Meaning, edited by W. Andrefsky, pp. 2-14. The University of Utah Press, Salt Lake City.

Bamforth, D.

1986 Technological efficiency and tool curation. American Antiquity 51:38-50.

Binford, L.

1979 Organization and formation processes: Looking at curated technologies. Journal of Anthropological Research 35:255-273.

1980 Willow smoke and dogs' tails: hunter-gatherer settlement systems and archaeological site formation. American Antiquity 45:4-20.

Chatters, J.

1987 Hunter-gatherer adaptations and assemblage structure. Journal of Anthropological Archaeology 6:336-375.

Cornejo, L., and L. Sanhueza

2003 Coexistencia de cazadores recolectores y horticultores tempranos en la cordillera andina de Chile central. Latin American Antiquity 14:389-407.

Cornejo, L., and J. Simonetti

1997-98 De rocas y caminos: Espacio y cultura en los Andes de Chile Central. Revista Chilena de Antropología 14:127143.

Escola, $\mathrm{P}$.

2004 La expeditividad y el registro arqueológico. Chungara Revista de Antropología Chilena Vol. Especial, Tomo I, pp. 49-60.

Galarce, $\mathrm{P}$.

2002 Cazadores Recolectores Tempranos en la Costa Sur de Semiárido: Aprovisionamiento y Procesamiento de Recursos Líticos. Thesis for Archaeologist degree, Departamento de Antropología, Facultad de Ciencias Sociales, Universidad de Chile. Santiago.

2004 Circulación de materias primas líticas y organización tecnológica en el semiárido meridional durante el Arcaico Temprano. Werken 5:21-25.

Galarce, P., L. Cornejo, C. Miranda, A. Peñaloza, G. Santander, P. Aguilera, and C. Uribe

2008 Estrategias tecnológicas de grupos humanos en la cordillera de Chile Central: Un análisis comparativo. Serie Arqueología, Primeras jornadas Nacionales de Cazadores Recolectores. Universidad Internacional SEK, Santiago, in press.

Gould, R., and S. Saggers

1985 Lithic procurement in Central Australia: A closer look at Binford's idea of embeddedness in Archaeology. American Antiquity 50:117-136.

Holdaway, S., S. Mcpherron, and B. Roth

1996 Notched tool reuse and raw material availability in French Middle Paleolithic sites. American Antiquity 61:377-387.
Jackson, D.

2002 Los Instrumentos Líticos de los Primeros Cazadores de Tierra del Fuego. Colección Ensayos y Estudios 4. Dirección de Bibliotecas, Archivos y Museos, Santiago.

Kelly, R.

1988 The three sides of a biface. American Antiquity 53:717734.

Miranda, C.

2008 Alteración intencional de materias primas líticas: El tratamiento térmico, una práctica tecnológica entre cazadores recolectores tardíos de Chile Central. Thesis for Archaeologist degree, Departamento de Antropología, Facultad de Ciencias Sociales, Universidad de Chile. Santiago.

Nelson, M.

1991 The study of technological organization. In Archaeological Method and Theory 3, edited by M. Schiffer, pp. 57-100. Universiy of Arizona Press, Tucson.

Odell, G.

2004 Lithic Analysis. Springer, New York.

Piel-Desrrouiseaux, J.

1989 Instrumental Prehistórico: Forma, Fabricación y Utilización. Ediciones Masson, Barcelona.

Price, D., and A. Gebauer, editors

1995 Last Hunters First Farmers. New Perspective on the Prehistoric Transition to Agriculture. School of American Research, Santa Fe.

Saavedra, M., and L. Cornejo

1995 Acerca de la cronología de El Manzano. Boletín de la Sociedad Chilena de Arqueología 21:31-34.

Shott, M.

1993 The Leavitt Site: a Parkhill Phase Paleo-Indian Occupation in Central Michigan. Memoirs of Museum of Anthropology 25. University of Michigan, Ann Arbor.

1994 Size and form in the analysis of flake debris: Review and recent approaches. Journal of Anthropological Method and Theory 1:69-110.

1996 An Exegesis of the curation concept. Journal of Anthropological Research 53:259-280.

Stafford, M.

1999 From Foragers to Farmer in Flint. A Lithic Analysis of the Prehistoric Transition to Agriculture in Southern Scandinavia. Aarhus University Press, Aarhus.

Tomka, $\mathrm{S}$.

2001 The effect of processing requirements on reduction strategies and tool form: a new perspective. In Lithic Debitage: Context, Form and Meaning, edited by W. Andrefsky, pp. 207-223. The University of Utah Press, Salt Lake City.

Whittaker, J.

1994 Flintknapping: Making and Understanding Stone Tools. University of Texas Press, Austin. 


\section{Notes}

1 The toolmaking quality of a specific raw material is based on the relationship of lithological attributes such as fracture type and grain size, as well as a qualitative determination of its suitability for use with certain techniques used to manufacture biface tools. Thus, raw materials that make concoidal fractures are fine grained, and are suitable for a complete repertory of flintknapping techniques (hard and soft percussion, pressure flaking) are assigned a high quality rating, while those with less favorable attributes are rated lower.
2 On this scale, we must obviously admit the theoretical existence of a strategy that is only expedient and that, therefore, has a value of 0 ; however, this value has not been used in this study; the lowest ratings assigned are between 0.20 and 0.25 . This is basically to conserve the mathematical relation, as values of 0 create many substantial difficulties for statistical tests applied to such values, thereby limiting their quantitative potential. 